\title{
At a Crossroads: Pakistani College Students' Perspectives on Service and Service-Learning
}

\author{
Emily A. Morrison
}

This article was originally published at:

https://journals.sfu.ca/iarslce/index.php/journal/article/view/228/169

Recommended Citation

Morrison, E. A. (2016). At a crossroads: Pakistani college students' perspectives on service and service-learning. International Journal of Research on Service-Learning and Community

Engagement, 4(1), 199-212. 


\title{
At a Crossroads: Pakistani College Students' Perspectives on Service and Service-Learning
}

\author{
Emily A. Morrison \\ The George Washington University
}

\begin{abstract}
With its large youth population, high unemployment, and limited educational opportunities, Pakistan is at a crossroads. Service-learning is a new concept in Pakistan, and several universities have begun to incorporate service into their curricula - with varying degrees of success - as a means for bridging academia with pressing community concerns. This qualitative case study explored Pakistani college students' perceptions of service and how service-learning was being developed at their university, and the challenges they had encountered. Findings revealed students' desire for a relevant education that not only prepares them for productive careers, but also serves their communities; gaps between the realities of and aspirations for education; issues of empowerment; and the need to mitigate risks. Analysis of the findings revealed a tension - a "tragic gap" (Palmer, 2004) - between what is and what could be in relation to service-learning and civic engagement in Pakistan.
\end{abstract}

Keywords: service-learning, student perspectives, Pakistan

"An invisible revolution is underway in higher education on all continents - a growing movement to educate active citizens and to apply university resources to community needs" (Innovations in Civic Participation, as cited in Plater, 2011, p. 53). While this revolution emerges, Bok (2006) asserted, "it is a safe bet that a majority of undergraduates complete their four years with very little preparation either as citizens or as professionals for the international challenges that are likely to confront them" (p. 233). Thus, the challenge for higher education is to prepare students simultaneously to be citizens who serve their communities in an increasingly interdependent world and to compete in a global job market, where preference is often given to those with global experience and knowledge (National Task Force, 2012; Plater, 2011). Service-learning offers a viable means for addressing both of these concerns (Battistoni, 2002; Saltmarsh, 2005), while also enhancing student learning (for seminal works, see Astin \& Sax, 1998, and Eyler \& Giles, 1999). Recognizing the potential of service-learning to support this revolution, five Pakistani and five U.S. universities started a multi-stage partnership in 2012 to cultivate civic engagement through the use of service-learning (Gottlieb \& Robinson, 2006) with funding from the U.S. State Department and Innovations in Civic Participation, a non-profit social change organization focused on promoting service and civic participation among youth around the world. In the first stage of this partnership, the participating institutions shared approaches, strategies, and challenges regarding servicelearning and civic engagement-new concepts for most Pakistani universities (Dean, 2007) — in order to set a foundation for future global service-learning ${ }^{1}$ exchanges.

Given the primary aim of enhancing civic engagement among college students (hereafter "students"), one strand of the Pakistani-U.S. partnership comprised an exploratory case study designed to understand Pakistani students' perspectives on service-learning (Bringle \& Hatcher, 2009; Tonkin, 2011). As Zlotkowski (2011) lamented, youth voice is often missing in research on service-learning. This is especially true in Pakistan, which represents not only one of the fastest growing populations in the world (IndexMundi, 2014), but also a country in which service-learning is in a nascent stage. Thus, the purpose

\footnotetext{
${ }^{1}$ Longo and Saltmarsh (2011) described global service-learning as a framework that bridges domestic and international service-learning by focusing on the outcomes of service-learning rather than the location of the service. They encouraged service-learners to "'be local' and 'think and act globally' regardless of context” (p. 83).
} 
of this article is to explore this unique case study, examining its contextual framework, delineating its methodology, and (re)presenting and discussing its findings.

\section{Contextual Framework}

\section{Pakistan}

Created in 1947 after World War II, Pakistan is a young country and is situated at a critical stage in its development (Dean, 2007, 2008). Growing from 32.5 million people in 1947 to over 186 million today (the sixth largest country in the world), almost $64 \%$ of Pakistan's population is under the age of 30 years (Broga, 2016), representing a "youth bulge" (Farooq, Idrees, Tariq, Ghulzar, \& Anwar, 2014). When handled thoughtfully through national strategies and policies, youth bulges can result in the meaningful engagement of youth in their communities, opportunities for quality education, and more secure livelihoods (Broga, 2016). However, research has shown that countries without such strategies have a greater propensity for violence and conflict, especially if educational and employment options are limited (Chandiramani, 2012; Farooq et al., 2014), as they are for many Pakistani youth. Overall, illiteracy rates in Pakistan are approximately 55\%, with the rate reaching $70 \%$ for women (UNICEF, 2012). Nearly half of primary-school-aged children are not enrolled in school (UNICEF, 2012). Meanwhile, Pakistan is facing its highest unemployment rate in the past 25 years, especially among young people - more than $60 \%$ of whom are employed are in unpaid, low paid, or unstable jobs (Broga, 2016). Thus, Pakistan is at a crossroads of either great crisis or great opportunity (Madsen, 2009). To prevent Pakistani youth from becoming more marginalized, vulnerable to violent groups, involved in unrest, and unable to contribute economically to the country (Farooq et al., 2014), Pakistani leaders are focusing attention on educating and engaging youth (Broga, 2016; UNICEF, 2012). This effort aligns with the rising demand for civic education in Pakistan (Dean, 2008; Haider, 2014; Hussain, 2007) which many Pakistani colleges are beginning to address through servicelearning.

\section{Service-Learning}

For the purposes of this article, service-learning is defined as:

a course-based, credit-bearing educational experience in which students (a) participate in an organized service activity that meets identified community needs, and (b) reflect on the service activity in such a way as to gain further understanding of course content, a broader appreciation of the discipline, and an enhanced sense of personal values and civic responsibility. (Bringle \& Hatcher, 2009, p. 38)

This definition synthesizes key elements of service-learning discussed in the literature and offers a foundation from which to explore service-learning experiences. The merits and limitations of servicelearning are well established. Seminal research on college student service and service-learning experiences has demonstrated positive outcomes around various measures such as course learnings, interpersonal skills, individual development, openness to new ideas, and understanding different perspectives (Astin \& Sax, 1998; Astin, Sax, \& Avalos, 1999; Astin, Vogelgesang, Ikeda, \& Yee, 2000; Eyler, Giles, \& Braxton, 1997). As revealed in these earlier studies, volunteering during college impacted students' longterm activities (assessed nine years later), including participating in community service work after college, helping others who were experiencing difficulty, promoting racial understanding, and feeling more socially responsible (Astin et al., 1999). Participating in service as an undergraduate student also significantly enhanced students' sense of civic responsibility, academic development, and overall lifeskill development (Astin \& Sax, 1998). Whereas all items on an assessment pertaining to civic responsibility increased in commitment for college service participants, one item- "influencing social values" (Astin \& Sax, 1998, p. 256) - actually declined among non-service participants. Indeed, by 
participating in reflective service activities connected to classroom studies, students can become civically engaged in the community (Ehrlich, 2000) and experience both cognitive and moral development (Delve, Mintz, \& Stewart, 1990).

The benefits of service-learning for civic engagement are of particular interest to educators in Pakistan (Aslam, Jaffary, \& Zaidi, 2011; Dean, 2007), where universities hope to engender such engagement among their students. To do so, it is helpful for educators and university leaders to reflect on and identify why they want to use service-learning. For example, Kendall (1990) posited that servicelearning should move students from a mindset of charity toward one of social justice. Students operating from a social justice mindset have the knowledge and skills to move beyond acts of charity to address the root causes of systemic social inequalities (Eyler \& Giles, 1999). Contrary to viewing service-learning as a linear continuum, Morton (1995) proposed three distinct paradigms: charity, project development, and social change. Each has its own worldview and "ways of identifying and addressing problems, and longterm visions of individual and community transformation" (p. 21), ranging from immediate needs to systemic issues. Within each paradigm, a distinction exists between "thin" and "thick" service. Thin service indicates a shallower response to a situation and comprises behaviors like imposing services on others, encouraging dependencies, raising false expectations, and magnifying inequalities. Thick service demonstrates integration and in-depth understanding of the complexity of situations by showing concern for why service is needed, matching means and ends, and investing in relationships.

Research has shown that the charity paradigm is often preferred to a social change paradigm among student service-learners (Bringle, Hatcher, \& McIntosh, 2006). Movement from one paradigm to another depends on whether or not dissonance occurs and how any felt dissonance is resolved (i.e., finding a new way or reverting to previous ways of thinking). Dissonance may emerge from a service-learning experience itself, a different context (especially international), the two taken together, or, for those serving abroad, when the student returns home (Kiely, 2004). Regardless of when or where it occurs, dissonance can be transformational, inviting people to learn about and accept novel ways of relating to and with the world, which are more effective than those of old paradigms. Yet, students may not accept the invitation. Thus, it is especially important to understand how students experience service-learning and dissonance (Giles, 2014), especially in Pakistan, whose culture and contexts differ from those explored in Kiely's (2004) research.

The differentiations between student perspectives and the quality of their engagement matter. Students bring to the classroom beliefs about and orientations toward charity and social change that shape learning outcomes (Moely, Furco, \& Reed, 2008). Over a two-year period, Moely, Furco, and Reed (2008) surveyed 2,233 students from seven different colleges enrolled in service-learning about their service preferences, experiences, and learning outcomes. Participants were divided into four preference groups: (1) charity; (2) social change; (3) high-value undifferentiated (i.e., equally positive about charity and social change); and (4) low-value undifferentiated (i.e., little interest in charity or social change). Matching service preference with the type of service experience resulted in students' greater satisfaction with their studies, increased feelings of interpersonal effectiveness and leadership, and greater learning about the community. However, the low-value undifferentiated group failed to show these positive outcomes. The researchers concluded that by aligning the type of service experiences with student preferences, servicelearning courses can be designed intentionally to enhance learning outcomes. It is unclear, however, whether the same holds true for those in Pakistan or for international experiences.

Exploring the nature and quality of service-learning is critical. The very language and concept of service-learning and civic engagement may not be universally understood (Erasmus, 2011). For example, meanings may not translate from one context to another (Sutton, 2011). In the U.S., these terms servicelearning and civic engagement are often entangled conceptually and when exported are "imbued with Western concepts of citizenship, democracy, service, and social justice" (Brabant, 2011, p. 109), which may not be appropriate in other contexts. Moreover, such explorations can guard against "mission vacationers" and "do gooders" (Illich, 1990; McKnight, 1989) - people who fail to examine their service intentions or consider the possible ramifications of their actions from the community's standpointwhether serving locally or internationally. Thus, it is imperative to examine what service-learning means and 
how it is practiced.

\section{Methodology}

In consideration of Pakistan's youth bulge, the call for civic engagement, missing student voices in research on service-learning, and the potential of service-learning to address academic and communityidentified needs in Pakistan, the purpose of this case study was to explore Pakistani students' perspectives of service-learning. The initial research question was, What are Pakistani students' perceptions of servicelearning? However, this question eventually broadened: What are Pakistani students' perceptions of service? (See Morrison, 2015, for further discussion about the evolution of the research question.)

Qualitative research methods were employed in this study due to the open-ended research question and the researcher's desire to understand unique experiences (Creswell, 2007; Kiely \& Hartman, 2011). Primary data comprised in-depth focus group responses. Secondary data included document analysis, participant observation (e.g., visiting community partner sites, observing student and faculty exchanges, attending presentations), and field notes (e.g., observations, clarifications to points raised in focus groups, decision points, and comments students shared with me in private about their experiences). The study followed Wendler's (2012) recommendations for ethical service-learning practice and research since no IRB review was available at the partner university in Pakistan.

The purposeful sample (Patton, 2002) included students from all regions of Pakistan who were enrolled at an urban Pakistani university and familiar with service-learning (Bringle \& Hatcher, 2009). The sample included students who had served in the community as part of the university's Community Service Club (which organized volunteer experiences) and/or had participated in the credit-bearing service course. Only a few students had completed the course and volunteered extensively. Thus, students' experiences with academic service-learning (Bringle \& Hatcher, 2009) ranged from none to limited, but their interest in and desire for it was high. Using snowball sampling starting with recommendations from university administrators and student leaders, potential participants were invited by e-mail to join the study. A total of 23 students participated, including 12 men and 11 women from urban, rural, and remote areas throughout the country.

The focus group included an overview of the purpose of the study, introductions, informed consent, and ground rules, as several students expressed concerns prior to the focus group about fear of reprisal by administrators. To mitigate any potential retaliation, the focus group co-created ground rules and agreed unanimously that everyone would keep what was shared and who shared it confidential; no names or identifying information would be included in reports or presentations of the data, and no videos or pictures of the group would be taken. Participants agreed to let me audio-record the session in order to transcribe it. All data sources were reviewed, coded, and analyzed using the constant comparative method (Lincoln \& Guba, 1985), resulting in emergent patterns about the students' perceptions of service. I triangulated the data (Merriam, 2002) by observing the students in different settings, following up with students one-onone, visiting community partner sites, and asking clarifying questions. To ensure trustworthiness and consistency in the analysis, interpretation, and representation of the data, I consulted with colleagues from the U.S. and Pakistan, reflected on my biases, and used an audit trail (Creswell, 2007; Patton, 2002).

\section{Findings}

Two caveats are worth noting here. First, as mentioned earlier, the research question shifted during the study. While Pakistani administrators asserted that service-learning was strong, the students expressed limited exposure to and experience with service-learning. Rather, all of the participants were involved in service and unanimously agreed on the importance of and desire for (more) service-learning experiences. Thus, in the findings, "service" reflects what was happening at the time of the study and "service-learning" indicates what students desired. Second, results from this study offer a snapshot in time of students' perceptions of service at one institution during Pakistan's formative years with service-learning and 
therefore are limited in their scope and transferability. With these caveats in mind, data analysis revealed four themes: (1) "service that matters"; (2) developing service-learning; (3) risk; and, (4) roles of administrators, faculty, and students in service-learning.

\section{"Service that Matters"}

Participants spoke passionately and simultaneously when the topic of quality service emerged. Overall, the concept of community service is "non-existent," and "service-learning is a new concept, not only in this university, but ... in Pakistan." However, the student participants, along with a few faculty, administrators, and community leaders, wanted to change that. The students agreed that more service options were needed and that they wanted service-learning. However, opinions varied when the topic of university-organized and -approved service arose. University-organized service events were described as "superficial":

I will give you two examples. One is the Eye Camp that they had yesterday on campus. It should have been inside [the] community or slums, or some other places where people cannot afford to get their eyes checked, to get medicines, to get eyeglasses. So it was really hard to have that on campus where most of the faculty, students, and staff can afford it. Secondly, they had a community awareness campaign and the brochures were in English and they were only on campus. It should have been off campus and the brochures should have been in Urdu, so that most of the population understands what is written.

While a few students thought that both of these university efforts were good, the majority of students were critical, calling for intentionally designed service. Moreover, there were several serious issues facing the community surrounding the university and their home communities elsewhere in Pakistan that needed their attention. Yet, the university did not allow students to address "sensitive" issues:

We are only allowed to do certain types of activities inside [the university] and only allowed to address certain issues. For example ... the administration did not allow [us] to have a tobacco/no-smoking awareness campaign because they said that the head of the [hospital name] is political. Political parties will have issues with it. Same with the breast awareness campaign.

The students raised important questions about what type of service was needed, as well as what service meant in the context of their lives, classrooms, the university, and the broader communities. They called for not only a thicker quality of engagement, but also an extension beyond a sole charity paradigm. Specifically, the students who took the service course decried that it had not been a "true service-learning experience." Students in the fields of engineering and medicine were "doing painting projects and picking up trash," activities that were "not directly relatable" to what the students were learning in class. Instead, the students expressed a deep desire for "service that matters," which directly connected their service experiences with their studies in meaningful ways (e.g., engineering students designing ramps to make buildings more accessible or medical students checking blood pressure or providing nutrition workshops). They also wanted an opportunity to reflect on their experiences and make sense of any dissonance that emerged. However, in addition to having few service experiences that related directly to their coursework, they asserted that there "was no reflection."

\section{Developing Service-Learning}

All of the students in the study stressed that their education "needs to be relevant" to "prepare me for a career" and "teach me how to solve the problems facing my community." They believed that servicelearning would help them achieve these aims and should therefore be developed while also offering a variety of opportunities ranging from "basic civics" to one-time experiences such as "blood drives" and "catastrophe responses." Though they desired thicker service-learning and social change experiences, their 
education was not providing either (Morton, 1995).

In order to develop service-learning, participants noted the importance of first identifying problems of educational culture, central coordination, scheduling, funding, and engagement quality. Before servicelearning can take hold, the "whole culture has to change. Grades are the only thing that matters right now." "Rote memorization and regurgitation of information must change." "We are studying all the time, yet [Pakistan] is not closing the gap in terms of how we compare to students in other countries." Assuming that the current educational climate could expand to include service-learning, the students then focused on developing communication plans using "a central system so that if there is an event going on, every department should know."

The participants asserted that the central system should also address the sensitive issue of scheduling. "We are in class from 9 to 6 every day." Departments "should give a timeslot so students can do [servicelearning]." However, when time was allotted for the community service course, that time was spent in "theoretical discussions rather than a class where we are engaged and working in the community." According to the current manner of implementing service-learning in Pakistan, the students felt that their service was infrequent, separate from, and not integrated into their coursework. Thus, they wanted more than a timeslot; they wanted the university to fund and support meaningful, quality service (as articulated earlier) that is integrated into class assignments and discussion.

\section{Risk}

Risk arose as a primary barrier to service-learning. Managing risk is imperative for any program, especially in areas with imminent threats to safety, security, and well-being. Risks from engaging in service-learning - whether natural or "manmade"-were categorized as either external or internal. External risks include physical safety, health, retaliation from people in power, and natural dangers. Internal risks include changes in awareness, thinking, feeling, and acting.

\section{External risks}

All of the participants were concerned with external risks including the potential for harm on the way to, from, and even at service sites; assault; war zones; exposure to illness or potentially dangerous conditions when working specifically in a health or natural disaster context; and leaders (from the university and community) retaliating against students or students' families by limiting opportunities, alienating the family, or imposing economic sanctions. For instance, one student from a provincial area bordering Afghanistan talked about the dangers of extremism and drone attacks. Other students discussed trying to take supplies to survivors of the 2013 earthquake, but roads were destroyed, and it was impossible to safely deliver the gathered supplies. Three biological sciences students articulated the responsibility they felt to share information about measles vaccines and polio with the community; however, "at the end of the day, if I decide to take my team and go to those areas, I am exposing them to a community of disease. And I can't do that." The risks associated with providing service must be calculated and weighed against the benefits to the community and students.

\section{Internal risks}

In addition to external risks, the students named several internal risks that affected how they saw, felt, thought, and acted. For instance, one veterinary student described his experience when he tried to implement an animal therapy program:

In America, they do animal therapy for cancer patients - people on the death bed, they bring animals, they make them pet them, they increase bonding between them. Over here, when we went to [the main hospital and asked] three oncologists, they said, "Are you guys crazy?" They're never going to say yes to you, because animals and patients? So we said, "Yes, we understand the implications, obviously, you know we'll take animals that have been pre-trained, prepped for that," but still ... 
This student's thinking was seen as different and radical. Other examples included descriptions of how local and national leaders, especially politicians, "are phobic to social media" after the Arab Spring, a time when there were waves of protests and demonstrations in Northern Africa and the Middle East, which were largely organized through social media (Jones, 2012). Thus, generally, students who think differently, try new ideas, get involved in service, and share their ideas and experience through social media are all taking risks.

\section{Roles of Administrators, Faculty, and Students in Service-Learning}

\section{Administrators}

The participants wanted unanimously for administrators to listen to their ideas and concerns and to actively support service-learning; however, they were dissatisfied with the university's response to date. "The administration doesn't even listen to us. We need more people in [the] administration who are more willing to listen." When asked how and with whom students could share their concerns about not being able to address certain issues or their feedback on the eye camp, for example, the students quickly replied, "Oh, we can't say anything! That would be really bad!" The students were noticeably afraid that "there would be negative repercussions." All of the participants agreed that the top administrators are the ones who set the tone of whether or not service-learning is valued, a point that was reiterated to me by four students in private. In order for service-learning to thrive, leaders need to listen, value the students' perspectives, and foster an educational culture that supports service-learning.

\section{Faculty}

Administrators create the conditions for service-learning, but faculty actually incorporate it into their courses and demonstrate service's role within their respective professions. The students repeatedly said, "faculty do not encourage students to go out and think, and come back in the classroom, discuss it, and think how we can solve [a community issue]." "We are discouraged from asking questions." Students were forced to "memorize the material and pass the exams," rather than being encouraged to think critically or "really learn." In order to change the current practice, participants said that faculty "need to learn how to teach using service-learning" so that they can prepare "us with the skills we need." To do so, the participants advocated for faculty training on how to implement service-learning.

\section{Students}

While administrators and faculty develop and implement service-learning, the students must accept a new way of learning. The participants spoke animatedly about student voice and involvement. Participants differed in the degree to which they felt students could and should be involved in service and servicelearning. They complained that not enough students were involved in either and were simultaneously frustrated that "the same people are always involved." One of the challenges they identified was in "spreading the word" about opportunities. Yet, another participant countered, "We can tell them, but they do not get involved."

Theories about why students do not get involved varied. Beyond the barriers previously discussed, such as risks and an unsupportive educational context, the students asserted that their uninvolved peers "just don't know." One student said the answer was "khwari" and his fellow students nodded in agreement and talked at once. Khwari is slang meaning:

whenever there is something where [students] actually don't feel compelled to do something. It's an Urdu word. It basically means that it's either too difficult to do, or I can't be bothered to do it. So you just don't. Even if you have a 30\% inclination to do it, you'll be like, you know, it's too difficult, so just forget it.

Khwari connotes a sense of hard work and laboriousness. Participants asserted that students often 
avoid the issues and do not get involved because they feel overwhelmed with the extent of the challenges facing communities, lack awareness of how-let alone where - to begin, lack the requisite skills or knowledge to address the issues, or hesitate to take on work that "detracts from [their] studies" and is unrewarded. To address khwari and low student involvement in service and service-learning, the participants agreed that students must become aware of such opportunities and be guided in learning about the issues, including the ways in which they can make a difference.

Students' voice. In addition to becoming aware and getting involved in their respective communities, participants identified finding their voice and knowing how to use it as challenges to service-learning involvement. Using their voice meant speaking up for themselves, speaking up for others in the community, speaking truth to perceived wrongs, and, for some, even taking action. While the students recognized issues in the community and wanted to speak up and act, they felt "disempowered" and as if "we don't have a voice." One student, who challenged me at the very start of the focus group regarding the U.S.'s role in drone strikes and foreign aid remarked, "You're sitting here, and you're still listening to me. But we aren't capable of going and telling our people this, because they don't have the ability to listen." Students who already had difficulty raising their voices felt even more marginalized when they tried to speak up and were not heard by leaders in their community or on campus. One quieter man in the focus group added, "A boy in a village can't do that [i.e., speak up or speak back to leaders]. Because he has to live there. So the people above him won't let him speak." "You can raise the issues to the municipal authorities and everything, but they won't listen to you. So people won't approach them." Yet, the students were aware of the issues, wanted to help problem-solve, and wanted to use their voices. They want to help people in their home communities who "do not even know they have rights."

Given the context in and out of the classroom and around the country, however, having and using their voices could have real educational, physical, and economic consequences for the students and their families. For some, deciding whether or not to use their voices was difficult and required weighing the risks - an external risk of potential retaliation and harm for speaking up and, simultaneously, an internal risk of potential psychological harm for swallowing their words and not acting when they felt they should.

\section{Summary}

The participants agreed unanimously that service is important and should be a part of their educational experience. According to the participants, in order to make this a reality, administrators and faculty need to value service-learning, learn how to incorporate service into the curriculum, collaborate with community partners on identifying relevant service opportunities, reduce barriers for participation, and listen to students and community partners. Students need to learn when, where, and how to use their voices to collaborate with community members and one another in meaningful ways that encourage others to get involved, serve, and address community concerns.

\section{Discussion}

The findings of this study directly reflect the invisible revolution that is happening around the world, which demands that institutions of higher education educate active citizens and address communityidentified needs (Plater, 2011) in ways that reflect the complexity and challenge of an interdependent world (Bok, 2006). Students are hungry for this education, and it is clear that communities near and far are facing real, consequential challenges that could be addressed through collaborative work (Dean, 2007). In resituating and incorporating this and the other study findings into the literature, four points emerge that warrant a deeper discussion than what has already been presented. These points include: relevant education, gaps between what is and what could be, empowerment (i.e., power and voice), and managing risk.

\section{Relevant Education}

The student participants believed that their university could do a better job of preparing them for their 
careers and lives as global citizens. They wanted the opportunity to engage in service-learning but asserted that the lectures, testing, back-to-back class times, and educational climate prevented the realization of service-learning. Underlying such a call for service-learning is a significant shift from a formal, hierarchical, and teacher-centered educational culture to one that is student-centered and democratic, which has also been called for by Pakistani scholars (Dean, 2007, 2008; Naseem, 2013; Nazir, 2010). While some students, faculty, administrators, and community partners at the study university are ready for (if not already acting on) this shift, the majority of those in the university and the country are not (Nazir, 2010). However, robust service-learning experiences could address students' desire for an education that prepares them for their careers and for the challenges facing their communities.

Bolstering the participants' desire for a meaningful education, Erasmus (2011) asserted that the overarching mission of higher education must remain connected to the public good:

Higher education institutions all over the world are bound to become irrelevant if they forget that serving the public interest (or the public good) in a knowledge-based way is their raison d'etre. The rapid pace of change everywhere thus forces higher education to place itself at the forefront of transformative thinking, and engaging deeply with the world at a local, national, international, and global level is a prerequisite for this. (p. 352)

Service-learning offers one way for colleges and universities to engage in the collaborative, creative thinking that is needed to transform communities into more inclusive and socially just spaces and places. Engaging in this work, however, can upset the status quo and shift power in ways that make current power holders uncomfortable. In fact, the threat of a loss in power can usher in authoritarian leadership (Davies, 2002), fostering a culture of fear that stifles, ignores, dismisses, and even brings harm to community members and their voices, and that limits education (Nazir, 2010) - a risk the participants identified explicitly.

\section{What Is and What Could Be}

In light of their desire for relevant education, the participants expressed varying degrees of frustration with how things were and how things could be with regards to service-learning and their education overall. Participants were frustrated that they did not even have the option of "real service-learning." They asserted that more meaningful experiential service experiences would better prepare them for "life after college." They all had ideas on how the community could address pressing concerns with support from the university and be strengthened through such efforts. The students' ideas and frustrations harkened to what Palmer (2004) called the "tragic gap"- that is, "the gap between the way things are and the way we know they might be" (p. 175). Morton (1995) referred to this phenomenon as an ironic "gulf between intention and action" (p. 31). The students were caught between what their universities espouses and what their institutions actually provided.

When caught in the tragic gap, Palmer (2004) explained, it is difficult to:

keep our grip on both reality and hope, we often find the tension too hard to hold - so we let go of one pole and often collapse into the other. Sometimes we resign ourselves to things as they are and sink into cynical disengagement. Sometimes we cling to escapist fantasies and float above the fray. (p. 175)

This description of standing in the tragic gap offers a lens through which to view the participants' perceptions of service and service-learning. The participants identified a tragic gap at the institutional level between the universities' intentions and actions, as well as a tragic gap on an individual level: khwari on the one hand and "times are changing and soon we will have no issues" on the other. Students were drawn to service-learning and acknowledged a pull between volition and destiny; hard work and fate; cynicism and hope; silence and voice; and, apathy and engagement. 


\section{Empowerment}

In analyzing the emergent issues of power and voice, participants spoke about not feeling empowered. Community psychologists define empowerment as "an intentional, ongoing process centered in the local community involving mutual respect, critical reflection, caring, and group participation through which people lacking an equal share of valued resources gain greater access to and control over those resources" (Cornell Empowerment Group, as cited in Maton, Seidman, \& Aber, 2011, p. 2). Ultimately, empowerment involves citizens, not professionals, determining how to address issues facing the community. All of the participants had ideas about how things did and did not work in their communities and with service-learning. They expressed a desire to contribute their ideas, talents, and resources (namely in the form of time) in ways that helped to close the gap between engaging in their communities and exceling in the classroom. They wanted to be part of the dialogue (voice) and solution (power). "Power relates here not only to what is spoken, but who gets to say it and how it is "said' (which includes action)" (Noyes, 2005, p. 537). As Noyes aptly observed, "voices are nothing without hearers" (p. 536).

When voicing their ideas, the students described being silenced, dismissed, ignored, or limited in scope (i.e., they could only offer ideas for service on certain topics). These encounters sent the message that their voices did not matter, reflecting larger cultural, political, and educational systems (Quiroz, 2001) and barriers that potentially discouraged or disallowed service-learning and community engagement (Nazir, 2010). These experiences of not being heard were painful and disempowering. Many of the participants were afraid to voice concerns, reflecting and affirming the persistence of an authoritarian educational climate (Davies, 2002) in Pakistan (Nazir, 2010; Rashid \& Mukhtar, 2012). While some students felt "shut down," others channeled that negative energy from not being heard into reflections on who else's voices had been silenced, ignored, or dismissed. Overall, the students expressed a need to find their voices and to know when, where, and how to use them in order to increase their chances of being heard in meaningful and effective ways when engaging with existing power holders and structures to create positive change.

\section{Mitigating Risk}

In voicing perspectives that differed from current norms (i.e., leaders' perspectives, power structures, or even one's own previous beliefs), mitigating risk was another major issue. Educators must continually balance potential benefits and risks by designing service-learning experiences that mitigate harm to students and the community. This is especially important when working across gender, religious, economic, racial, educational, age, sexual orientation, and political differences, examples of all of which emerged throughout this study. The students expressed real and perceived risks and barriers to service and service-learning for individuals and groups, which is not altogether surprising, given the current and historical context (Dean, 2007, 2008). However, all of the participants felt that university leaders could do more to develop service-learning by mitigating potential risks. Students felt that the administrators were overly conservative, limiting issues addressed and offering service on campus as opposed to in the community. They believed that more calculated risks could and should be taken, which would act to close (or at least narrow) the gap between what is and what could be in creating even more meaningful collegiate experiences.

\section{Future Research}

Reflecting on this discussion, more research is needed around how students recognize and experience standing in a gap. For instance, the results of this case study raise a number of questions that demand attention. What are the costs (e.g., psychological, emotional, developmental) of standing in the tragic gap? How does dissonance affect student growth, student learning, and, on a broader level, social transformation? Does standing in the tragic gap offer a potentially transformative experience at an individual and/or collective level? How might transformative experiences be affected by the context and location (i.e., domestic or international) of service? For students who do service-learning with universities in communities (within their home country) that differ significantly from their home communities (i.e., 
conservatism, liberalism, religiosity, leadership, power structures, inclusivity, etc.), do the students experience dissonance like those who engage in international service-learning (Giles, 2014; Kiely, 2004)? Is the experience of dissonance similar to that of standing in a tragic gap? Moreover, do higher education faculty, administrators, and community leaders recognize, acknowledge, and prepare students for the internal and external risk taking that service-learning can elicit? To what extent do students have the tools and support they need to work with and through the cognitive dissonance that can arise (Kiely, 2004) during a service experience? How do all of these experiences shape students' paradigms of service (Bringle et al., 2006; Morton, 1995), learning outcomes (Moely et al., 2008), and much-needed community change (Dean, 2008)?

\section{Implications}

Considering the findings that emerged from this study around relevant education, bridging the gap between what is and what could be, empowerment, and mitigating risk, students and service-learning stakeholders are faced with options about how to actualize higher education's mission and make informed decisions when facing crossroads. The participants in this study looked to educators to create opportunities for meaningful service-learning experiences. To develop such opportunities, changes in the educational culture and the university itself are needed, but these are often difficult to bring about. Initial responses to change typically are not positive or negative; rather, they are ambivalent (Piderit, 2000). Ambivalence involves cognitive, emotional, and intentional states that emerge in response to situations in which at least two alternative perspectives are strongly experienced at the same time (Piderit, 2000). For example, faculty members may be interested in incorporating service-learning into their courses but may hesitate to do so if such efforts are not valued by the institution or may go against current educational and cultural norms. Students may want to work in the community but may worry that their involvement will adversely affect their grades. Similarly, students may want to voice their concerns and, at the same time, fear retaliation for speaking honestly. Ambivalence does not imply a lack of caring; rather, it is the experience of being pulled in two directions because one cares about both and is standing in a tragic gap (Palmer, 2004).

If harnessed, ambivalence and its inherent multidimensionality can offer new insights and an opportunity for dialogue (Bohm, 1996) that yields more creative insights into difficult issues and situations, such as Pakistan's youth bulge, by focusing attention on the core issues raised by change (Piderit, 2000). Change is inherent to learning, particularly global service-learning. The study participants courageously named and shared their insights and experiences of service. In doing so, they called for changes that included more listening, meaningful service integrated into their respective courses of study, leadership by faculty and administrators to create or expand service-learning opportunities, mitigating risks, and finding and using their voices as students. These findings offer an initial understanding of service experiences in Pakistan for students who will continue to evolve with and in response to changes in the local and national context.

\section{Conclusion}

The evidence from this study is clear: Pakistan is at a crossroads. The youth bulge, exacerbated by limited educational and employment opportunities, is creating a crisis. The Chinese character for crisis consists of two symbols that stand for threat and opportunity. The threats facing Pakistani youth include escalating marginalization, vulnerability for joining violent groups, and unpreparedness for professional work. Yet, the participants in this study were brimming with potential. This study revealed passionate students who wanted to contribute to their communities now and in the future through their academic and professional work. They yearned for an education that was relevant and that incorporated meaningful service, supporting an invisible revolution (Plater, 2011) in Pakistan. Service-learning may in fact provide a way to bridge students' experience of standing in the tragic gap, enabling them to balance learning and address community-identified concerns in ways that not only empower them and their communities, but also 
transform the looming crisis into opportunities.

\section{Author Note}

Emily A. Morrison, Human Services and Social Justice Program, and Department of Sociology, The George Washington University.

\section{Correspondence}

Correspondence regarding this article should be addressed to Emily A. Morrison, Director, Human Services and Social Justice Program, and Assistant Professor of Sociology, The George Washington University, 409F Phillips Hall, $80122^{\text {nd }}$ Street, NW, Washington DC, 20052. Phone: (202) 994-6167. Email: emily_m@gwu.edu

\section{References}

Aslam, R., Jaffary, T, \& Zaidi, Z. (2011). Service-learning: Increasing civic responsibility in Pakistani students. Medical Education, 45, 524.

Astin, A. W., \& Sax, L. J. (1998). How undergraduates are affected by service participation. Journal of College Student Development, 39(3), 251-263.

Astin, A. W., Sax, L. J., \& Avalos, J. (1999). Long-term effects of volunteerism during the undergraduate years. Review of Higher Education, 22, 187-202.

Astin, A. W., Vogelgesang, L. J., Ikeda, E. K, \& Yee, J. A. (2000). Executive summary: How service learning affects students. Los Angeles: Higher Education Research Institute, UCLA.

Battistoni, R. (2002). Civic engagement across the curriculum: A resource book for service-learning faculty in all disciplines. Providence, RI: Campus Compact.

Bohm, D. (1996). On dialogue. New York: Routledge.

Bok, D. (2006). Our underachieving colleges: A candid look at how much students learn and why they should be learning more. Princeton, NJ: Princeton University Press.

Brabant, M. (2011). Service-learning: An exportable pedagogy? In T. Stewart \& N. Webster (Eds.), Problematizing service-learning: Critical reflections for development and action (pp. 107-128). Charlotte, NC: Information Age Pub.

Bringle, R. G., \& Hatcher, J. A. (2009). Innovative practices in service learning and curricular engagement. In L. Sandmann, A. Jaeger, \& C. Thornton (Eds.), New directions in community engagement (pp. 37-46). San Francisco, CA: Jossey-Bass.

Bringle, R. G., Hatcher, J. A., \& McIntosh, R. E. (2006). Analyzing Morton's typology of service paradigms and integrity. Michigan Journal of Community Service Learning, 13(1), 5-15.

Broga, D. (2016). Youth bulge or bomb? Harnessing the potential of Pakistani youth. London: London School of Economics and Political Science. Retrieved from: http://blogs.lse.ac.uk/southasia/2016/05/13/youth-bulge-or-bomb-harnessing-the-potential-ofpakistani-youth/

Chandiramani, P. (2012, October 26). Youth bulge, public policy, and peace in Pakistan. New Security Beat. Retrieved from http://www.newsecuritybeat.org

Creswell, J. W. (2007). Qualitative inquiry and research design: Choosing among five approaches. Thousand Oaks, CA: Sage Publications.

Davies, L. (2002). Possibilities and limits for democratisation in education. Comparative Education, 38, 251-266.

Dean, B. L. (2007). Research report: The state of civic education in Pakistan. Islamabad, Pakistan: Aga Khan University, Institute for Educational Development.

Dean, B. L. (2008). The changing face of citizenship education in Pakistan. In J. Arthur, I. Davies, and C. Hahn (Eds.), SAGE Handbook of Education for Citizenship and Democracy (pp. 227-238). Thousand 
Oaks, CA: Sage.

Delve, C. I., Mintz, S. D., \& Stewart, G. M. (1990). Promoting values development through community service: A design. In C. Delve, S. Mintz, and G. Stewart (Eds.), Community service as values education. New directions for student services (no.50). San Francisco: Jossey-Bass.

Ehrlich, T. (Ed.). (2000). Civic responsibility and higher education. Phoenix, AZ: Oryx Press.

Erasmus, M. (2011). A South African perspective on North American international service learning. In R. Bringle, J. Hatcher, \& S. Jones (Eds.), International service learning (pp. 347-371). Sterling, VA: Stylus.

Eyler, J., \& Giles, D., Jr. (1999). Where's the learning in service-learning? San Francisco, CA: JosseyBass.

Eyler, J., Giles, D., Jr., \& Braxton, J. (1997). The impact of service-learning on college students. Michigan Journal of Community Service Learning, 4, 5-15.

Farooq, M., Idrees, M., Tariq, S., Ghulzar, F., \& Anwar, H. N. (2014). Consequences of youth bulge in Pakistan. Mediterranean Journal of Social Science, 5(20), 2216-2222.

Giles, H. C. (2014). Risky epistemology: Connecting with others and dissonance in community-based research. Michigan Journal of Community Service Learning, 20(2), 65-78.

Gottlieb, K., \& Robinson, G. (2006). A practical guide for integrating civic responsibility into the curriculum $\left(2^{\text {nd }}\right.$ ed.). Washington, DC: Community College Press.

Haider, M. (2014). Pakistan's need for civic education. Retrieved from http:/www.dawn.com/news/1097292/pakistans-need-for-civic-education

Hussain, S. (2007). Why civic education is a must. Karachi, Pakistan: Aga Khan University, Institute for Educational Development. Retrieved from http://ecommons.aku.edu/cgi/viewcontent.cgi?article=1102\&context=pakistan ied pdck

Illich, I. (1990). To hell with good intentions (reprint of 1968 speech). In J. Kendall (Ed.), Combining service and learning (pp. 314-320). Raleigh, NC: National Society for Internships and Experiential Education.

IndexMundi. (2014). Fact book: Pakistan. Retrieved from http://www.indexmundi.com/pakistan

Jones, P. (2012). The Arab Spring: Opportunities and implications. International Journal, 62(2), 447-463.

Kendall, J. C. (1990). Combining service and learning: An introduction. In J. Kendall \& Associates (Eds.), Combining service and learning: A resource book for community and public service, vol. 1 . (pp. 1-36). Raleigh, NC: National Society for Internships and Experiential Education.

Kiely, R. (2004). A chameleon with a complex: Searching for transformation in international service learning. Michigan Journal of Community Service Learning, 11, 5-20.

Kiely, R., \& Hartman, E. (2011). Qualitative research methodology and international services learning: Concepts, characteristics, methods, approaches, and best practices. In R. Bringle, J. Hatcher, \& S. Jones (Eds.), International service learning (pp. 291-317). Sterling, VA: Stylus.

Lincoln, Y. S., \& Guba, E. G. (1985). Naturalistic inquiry. Beverly Hills, CA: Sage.

Longo, N. V., \& Saltmarsh, J. (2011). New lines of inquiry in reframing international service learning into global service learning. In R. Bringle, J. Hatcher, \& S. Jones (Eds.), International service learning (pp. 69-85). Sterling, VA: Stylus.

Madsen, E. L. (2009). Pakistan's demographic challenge is not just economic. New Security Beat. http://www.newsecuritybeat.org/2009/11/pakistans-demographic-challenge-is-not-just-economic

Maton, K. I., Seidman, E., \& Aber, M. S. (2011). Empowering settings and voice for social change. New York: Oxford University Press.

McKnight, J. (1989). Why "servanthood" is bad. The Other Side, 25, 38-42.

Merriam, S. B. (2002). Qualitative research in practice. San Francisco, CA: Jossey-Bass.

Moely, B. E., Furco, A., \& Reed, J. (2008). Charity and social change: The impact of individual preferences on service-learning outcomes. Michigan Journal of Community Service Learning, 15(1), $37-48$.

Morrison, E. A. (2015). How the I shapes the eye: The imperative of reflexivity in global service-learning qualitative research. Michigan Journal of Community Service Learning, 22(1), 52-66. 
Morton, K. (1995). The irony of service: Charity, project, and social change in service-learning. Michigan Journal of Community Service Learning, 2, 19-32.

Naseem, N. R. (2013). Peer mentoring: Enhancing social cohesion in Pakistani universities. Higher Education, Skills and Work-Based Learning, 3, 130-140.

National Task Force on Civic Learning and Democratic Engagement. (2012). A crucible moment: College learning and democracy's future. Washington, DC: Association of American Colleges and Universities.

Nazir, M. (2010). Democracy and education in Pakistan. Educational Review, 62, 329-342.

Noyes, A. (2005). Pupil voice: Purpose, power, and the possibilities for democratic schooling. British Educational Research Journal, 31(4), 533-540.

Palmer, P. (2004). A hidden wholeness. San Francisco, CA: John Wiley \& Sons.

Patton, M. (2002). Qualitative research and evaluation methods (3rd ed.). Thousand Oaks, CA: Sage.

Piderit, S. (2000). Rethinking resistance and recognizing ambivalent attitudes toward organizational change: A multidimensional view. Academy of Management Review, 25, 783-794.

Plater, W. (2011). The context for international service-learning: An invisible revolution is underway. In R. Bringle, J. Hatcher, \& S. Jones (Eds.), International service learning (pp. 29-56). Sterling, VA: Stylus.

Quiroz, P. A. (2001). The silencing of Latino student "voice": Puerto Rican and Mexican narratives in eighth grade and high school. Anthropology and Education Quarterly, 32(3), 326-349.

Rashid, K., \& Mukhtar, S. (2012). Education in Pakistan: Problems and their solutions. International Journal of Academic Research in Business and Social Sciences, 2, 332-343.

Saltmarsh, J. (2005). The civic promise of service learning. Liberal Education, 91(2), 50.

Sutton, S. B. (2011). Service learning as local learning: The importance of context. In R. Bringle, J. Hatcher, \& S. Jones (Eds.), International service learning (pp. 125-144). Sterling, VA: Stylus.

Tonkin, H. (2011). A research agenda for international service learning. In R. Bringle, J. Hatcher, \& S. Jones (Eds.), International service learning (pp. 191-224). Sterling, VA: Stylus.

UNICEF (2012). Situation analysis of children and women in Pakistan. Islamabad, Pakistan: United Nation's Children's Fund. Retrieved from http://www.unicef.org/pakistan/National_Report.pdf

Wendler, R. (2012). Human subjects protection: A source for ethical service-learning practice. Michigan Journal of Community Service Learning, 18, 29-39.

Zlotkowski, E. (2011). Emerging voices, challenging perspectives. Michigan Journal of Community Service Learning, 17, 59-64. 